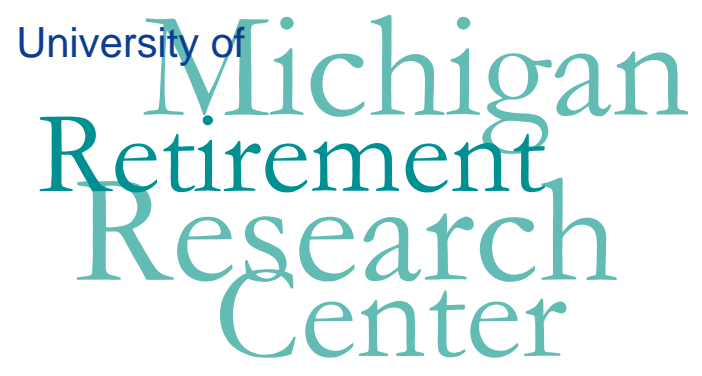

Working Paper

WP 2006-121

\title{
Social Security and Retirement Dynamics
}

Alan L. Gustman and Thomas Steinmeier

\begin{tabular}{|l|l|l|}
\hline $\mathrm{M}$ & $\mathrm{R}$ \\
\hline $\mathrm{R}$ & $\mathrm{C}$ & \\
\hline
\end{tabular}$\quad$ Project \#: UM05-05 


\title{
"Social Security and Retirement Dynamics"
}

\author{
Alan L. Gustman \\ NBER and Dartmouth College \\ Thomas Steinmeier \\ Texas Tech University \\ July 2006 \\ Michigan Retirement Research Center \\ University of Michigan \\ P.O. Box 1248 \\ Ann Arbor, MI 48104 \\ http://www.mrrc.isr.umich.edu/ \\ (734) 615-0422
}

\section{Acknowledgements}

This work was supported by a grant from the Social Security Administration through the Michigan Retirement Research Center (Grant \# 10-P-98358-5). The findings and conclusions expressed are solely those of the author and do not represent the views of the Social Security Administration, any agency of the Federal government, or the Michigan Retirement Research Center.

\section{Regents of the University of Michigan}

David A. Brandon, Ann Arbor; Laurence B. Deitch, Bingham Farms; Olivia P. Maynard, Goodrich; Rebecca McGowan, Ann Arbor; Andrea Fischer Newman, Ann Arbor; Andrew C. Richner, Grosse Pointe Park; S. Martin Taylor, Gross Pointe Farms; Katherine E. White, Ann Arbor; Mary Sue Coleman, ex officio 


\title{
Social Security and Retirement Dynamics
}

\author{
Alan L. Gustman and Thomas Steinmeier
}

\begin{abstract}
This paper is based on a structural model of retirement and saving, estimated with data for a sample of married men in the Health and Retirement Study. It explains the relation of specific features of Social Security -- the benefit amount, the early entitlement age, the normal retirement age, earnings test parameters, and the delayed retirement credit -- to the full range of retirement outcomes -- continued work on the main job, full time work outside the main job after a period of partial or full retirement, as well as partial retirement and full retirement. The project also estimates the relation of Social Security to the flows among these states. We consider not only the effect of Social Security on movement from states of greater to lesser work, the probability of either moving from full time work to partial retirement or directly to full retirement, or from partial retirement to full retirement, but the reverse flows from states of lesser work to states of greater work.
\end{abstract}

The largest effects of the policies examined are from increasing the early entitlement age from 62 to 64 and reducing benefits to 75 percent of their promised levels, the approximate amount benefits would have to be reduced when the trust fund runs out if there are no changes in funding. With the older early entitlement age, about 5 percent more of the population continues to work full time at their main job at 62 and 63 than would otherwise. In addition, another 4.5 percent of the male population works full time after having retired, as does another 4 percent at age 63. Partial retirement is reduced at ages 62 and 63 by about 3 percentage points when the early entitlement age is 64 . Overall, complete retirements are about 6 percentage points lower at 62 and 63 when the early retirement age is higher. From age 64 on, the percent completely retired is about two percentage points lower in each year when the early entitlement age is 64 rather than 62.

The effects of reducing promised Social Security benefits by about a quarter are also large. The probability of remaining on the main job is higher for those in their sixties, with the difference ranging from 3 to 5 percentage points for those ages 62 and older. At each year of age, an additional 1 percentage point will be in full time work after having retired. There is little difference in the fraction partially retired, so the probability of being fully retired is reduced by 4 to 6 percentage points when benefits are reduced by a quarter. 
This paper explains the relation of specific features of Social Security, the benefit amount, the early entitlement age, the normal retirement age, the earnings test parameters and the delayed retirement credit, to the full range of retirement outcomes - continued work on the main job, full time work outside the main job after a period of partial or full retirement, as well as partial retirement and full retirement. The paper also estimates the relation of Social Security to the flows among these states. The analysis considers not only the effect of Social Security on movement from states of greater to lesser work, the probability of either moving from full time work to partial retirement or directly to full retirement, or from partial retirement to full retirement, but the reverse flows from states of lesser work to states of greater work.

Descriptive data have explored how the relative importance of full time work, partial retirement and full retirement change with age (Gustman and Steinmeier, 1984, 2000; Maestas, 2005). Quasi-experimental studies attempt to isolate the size of the effects on retirement of various aspects of Social Security policies that have already been implements. A recent example is Manchester and Song's (2006) analysis of the effects of the abolition of the earnings test after normal retirement age. A number of dynamic, stochastic models are in the same spirit as our work. Those closest to our current analysis are Rust and Phalen (1997), French (2005), and van der Klaauw and Wolpin (2005), who attempt to isolate preferences for retirement and saving while carefully specifying budget constraints in a way that will permit policy analysis. Each of these studies has a somewhat different emphasis. Given our interest in estimating the overall effects of Social Security and pensions, our work emphasizes the role of pensions, while Rust and Phalen and van der Klaauw and Wolpin exclude those with pensions from their analyses. French (2005) takes a step toward including pensions in his analysis, but he does not use individual data on pension plan incentives. 
It is useful to consider briefly how the current paper relates to our earlier structural work modeling retirement and simulating the effects of policy, and to note in turn how that work relates to the contributions of others. Our earlier papers, beginning with Gustman and Steinmeier (1986), assumed perfect foresight and so were unable to explain reversals among retirement states. They also assumed perfect capital markets. Gustman and Steinmeier (2005) introduced imperfect capital markets and heterogeneity in time preference into a joint model of retirement and saving. This research demonstrates that if an empirical analysis is to explain the effects of Social Security on such key features of the retirement hazard as the spike in retirement activity at ages 62 and at normal retirement age, the behavioral analysis must explain both retirement and saving at the same time. Gustman and Steinmeier (2002b) explores the effects of introducing stochastic elements into a model of retirement and saving. But unlike the present paper, the latter model only analyzes the decision to leave the labor market entirely. It does not explain the relation of Social Security to partial retirement, or to flows among the states of full time work, partial retirement and full retirement.

Because most of the policies we analyze here have not yet been implemented, and they are embedded in a complex system, the likely sizes of changes in behavioral outcomes induced by these policies are difficult to predict without resorting to a structural model. Thus the aim of the present paper is to provide a firmer understanding of how current and proposed Social Security policies are likely to affect the flow of older persons through various retirement states.

Section II specifies and estimates the structural model of retirement and saving with partial retirement and stochastic asset returns that underlies our analysis. Section III uses the model to examine the effects of alternative Social Security policies. Section IV concludes. 


\section{A Structural Model of Retirement and Saving with Partial Retirement and Stochastic Asset Returns}

The model takes a standard life cycle approach in which individuals maximize expected utility subject to an asset evolution constraint. Consumption and leisure over the lifetime are the choice variables in the model. The stochastic variables include the returns to assets, mortality outcomes, and retirement preferences. Potential wages and health are treated as exogenous and non-stochastic. In a more general model these variables would also be treated as stochastic, but doing so would render the model almost computationally intractable. In the choice of which variables to make stochastic, stochastic stock returns can be introduced without requiring additional state variables, which exponentially add to the computational burden. Additionally, while uncertainties about future health and wages have some effect on savings and assets, we believe that most of the considerable assets which are accumulated prior to retirement are the result of individuals' basic savings propensities, and not precautionary against bad outcomes on wages and health.

\section{A. Specification of the model.}

In the model, for each year $\mathrm{i}$, the individual chooses consumption $\mathrm{C}$ and leisure $\mathrm{L}$ to maximize expected utility:

$$
\mathrm{EU}_{\mathrm{i}}=\mathrm{E}_{\mathrm{i}}\left[\sum_{\mathrm{t}=\mathrm{i}}^{\mathrm{T}}\left\{\mathrm{e}^{-\rho \mathrm{t}} \sum_{\mathrm{m}=1}^{3} \mathrm{~s}_{\mathrm{m}, \mathrm{t}}\left(\frac{1}{\alpha} \mathrm{C}_{\mathrm{m}, \mathrm{t}}^{\alpha}+\mathrm{h}_{\mathrm{t}} \mathrm{L}_{\mathrm{m}, \mathrm{t}}^{\gamma}\right)\right\}\right]
$$

$\mathrm{L}$ takes on a value of 1 if the individual is retired, 0 if he or she is working, and 0.5 if the individual is partially retired. $h_{t}$ indicates the strength of the individual's preference for retirement, which may vary from one person to the next. $\rho$ is the time preference rate, which also may vary from one person to the next. 
In this paper, we consider individuals who are part of couples. Given the complexity of the calculations, we take the income of the spouse to be exogenous and non-stochastic. The individual does take into account the consumption possibilities of the spouse after he or she is deceased. The index $\mathrm{m}$ takes on three values indicating whether both members of the couple survive until year $t$, only the individual survives, or only the spouse survives. $\mathrm{s}_{\mathrm{m}, \mathrm{t}}$ is the probability that the household will have the composition described by $m$ in year t. T corresponds to the maximum age beyond which the household's survival probabilities are too small to matter.

The asset constraint is given by

$$
A_{t}=\left(1+r_{t}\right) A_{t-1}+W_{t}\left(1-L_{m, t}\right)+E_{m, t}+B_{m, t}-C_{m, t}
$$

$A_{t}$ is the level of assets in year $t$, and $r_{t}$ is the stochastic return on those assets in year $t$. Assets are assumed to start out at 0 at the beginning of the working life and are not permitted to be negative. $\mathrm{W}_{t}$ is the wage rate at time $t$, which will depend on whether the individual has stayed on his or her career job, which we also label as his or her main job, or has previously retired and is going back to work. The career (main) job is considered to be the job the individual holds until he fully or partially retires for the first time. The term $\mathrm{E}_{\mathrm{m}, \mathrm{t}}$ is the income accruing to the spouse, including earnings and pensions. The spouse is assumed to have a retirement date unaffected by the individual's choices, and the term is taken to be zero in states where the spouse is no longer alive.

$\mathrm{B}_{\mathrm{m}, \mathrm{t}}$ is the amount of the individual's pension and the household's Social Security benefits, both of which will be affected by the individual's retirement decisions. For defined benefit pensions, the benefit amount is determined by the retirement date and continues until death. For defined contribution pensions, the contributions are put into an account and allowed 
to accrue subject to the same stochastic return as is applied to assets. The account is assumed to be made available to the individual when the individual retires from the career job. Household Social Security benefits are calculated according to the Social Security rules, depending on previous retirement decisions and the composition of the surviving household. Since most individuals claim benefits as soon as eligible (Coile et al., 2002; Gustman and Steinmeier, 2002a), we do not try to model the acceptance decision here and instead assume that the individuals will claim the benefits as soon as they can, consistent with the earnings test.

Individuals are assumed to be heterogeneous with regard to both their time preference rate and their retirement preferences. With regard to time preference, we assume that $\rho$ has a different value for different individuals and essentially treat it as a fixed effect in the estimation. ${ }^{8}$ Retirement preferences are reflected in the coefficient to the leisure term in the utility function and are characterized by

$$
h_{t}=e^{\beta X_{t}+\varepsilon_{t}}
$$

The linear form $\beta \mathrm{X}_{\mathrm{t}}$ has three terms: a constant, age, and health status. The coefficient of age is taken to be positive, so that retirement gradually becomes more desirable as the individual ages and suffers from the cumulative effects of nature's aging. Note that there is no term which makes the individual suddenly more desirous of retirement at 62, 65, or any other particular age; this means that any spikes in retirement in the simulations are the result of idiosyncracies in the opportunity set, and not the result of preferences.

The $\varepsilon_{\mathrm{t}}$ term in $\mathrm{h}_{\mathrm{t}}$ reflects the individual's relative preference for leisure. An individual starts out with a value of $\varepsilon$ drawn from a distribution with mean 0 and standard deviation $\sigma_{\varepsilon}$

\footnotetext{
${ }^{8}$ In a different context, Ippolito (1997) makes differential time preference rates a central focus. His analysis concerns the employer demand for labor and the structure of pensions.
} 
and keeps this value until he or she retires from the career job. Upon retirement, the individual may find that retirement is more or less fulfilling than anticipated, or perhaps the individual may find that he values consumption relatively more than he had thought. In any case, experience allows the value of $\varepsilon$ to change after retirement, and the model reflects this by allowing the value of $\varepsilon_{\mathrm{t}}$ to vary after retirement, with values in successive years correlated with a correlation parameter $\rho_{\varepsilon}$. If the individual finds that retirement is substantially less fulfilling than anticipated, a return to work, albeit at a reduced wage as compared to the career job, may be the optimal decision.

$\mathrm{L}^{\gamma}$ is proportional to the utility value of leisure. It has a value of zero if the individual is working full time $(\mathrm{L}=0)$ and a value of one if the individual is fully retired $(\mathrm{L}=1)$. If the individual is partially retired $(\mathrm{L}=1 / 2), \mathrm{L}^{\gamma}=(1 / 2)^{\gamma}$ should take on a value between 0.5 and 1 if diminishing marginal utility of leisure is to be satisfied. Call this value $V_{p}$. If $V_{p}$ is close to unity, full time work is particularly onerous compared to partial retirement work, and most people should go through a period of partial retirement. If, on the other hand, $\mathrm{V}_{\mathrm{p}}$ is close to 0.5 , the marginal disutility of work is rising very slowly with additional work. As with time preferences and $\varepsilon$, we assume that individuals are heterogeneous with regard to their valuation of partial retirement leisure. For any individual, $\mathrm{V}_{\mathrm{p}}$ comes from a random draw from the truncated exponential distribution $\mathrm{f}(\mathrm{Vp})=\mathrm{ke}^{\delta \mathrm{V}_{\mathrm{p}}}$, defined on the interval 0.5 to 1 . For a given $\delta, \mathrm{k}$ is the value needed to make the distribution function integrate to unity over the interval. If $\delta$ is positive, values of $\mathrm{V}_{\mathrm{p}}$ toward unity will be more common, while if $\delta$ is negative, values near 0.5 will be more common.

The data suggest that partial retirement becomes relatively more common at later ages. At age 60 , partially retired workers are $10 \%$ of those working, with the figure rising to $19 \%$ at 
age 62 and $54 \%$ at age 68 . To accommodate the evidently increasing relative attractiveness of part-time work, we make $\delta$ a function of age: $\delta=\delta_{0}+\delta_{\mathrm{a}}$ Age. If $\delta_{\mathrm{a}}$ is positive, the distribution of $\mathrm{V}_{\mathrm{p}}$ shifts to the right over time, so that part-time work becomes relatively more attractive to full-time work, and hence more common. Individuals are assumed to maintain the same relative position in the distribution of $\mathrm{V}_{\mathrm{p}}$ 's even as that distribution shifts over time. The heterogeneity relates to where they are in that distribution. A similar problem occurs with respect to health, which greatly reduces the amount of partial retirement. When we tried to introduce health into the $\delta$ term in the same way we introduced age, the coefficient tended toward minus infinity, indicating that when a health problem causes an individual to retire, it usually causes complete retirement rather than partial retirement. To reflect these results, the value of $V_{p}$ is set to 0.5 for individuals with health problems.

The individual carries several state variables from one period to the next; these are variables which are consequences of past decisions and random events which have a bearing on the current decision. Five state variables are applicable in all periods. These are the level of assets $A_{t}$, the time preference rate $\rho$, the level of overall leisure preferences $\varepsilon_{t}$, the relative utility of part-time leisure $V_{p}$, and whether or not the individual is still in the career job. If the individual is still in the career job and that job has a defined contribution pension, there is another state variable relating to the size of the defined contribution balance. After the individual has left the career job, additional state variables related to the value of defined benefit pension amounts and Social Security benefits are introduced. Before retirement from the career job, the defined benefit and Social Security amounts are completely determined from the fact that the individual is still in the career job and thus do not have to be included as separate state variables. 
To summarize, the utility function contains three elements which are heterogeneous between different individuals. They are (1) the time preference rate $\rho,(2)$ the initial value of the overall leisure preference term $\varepsilon$, and (3) the relative attractiveness of part-time vs. full time work, as reflected in $\mathrm{V}_{\mathrm{p}}$. In the estimation and subsequent simulations, the time preference rate is taken as a fixed effect whose value is calculated for each individual, while $V_{p}$ and the initial value of $\varepsilon$ are treated as random effects whose values are drawn from the specified distributions.

\section{B. Solution to the model.}

As with any stochastic dynamic model, the solution of the model proceeds backwards. In the final year $\mathrm{T}$, for each point in a grid of points in the career job-retirement preference-time preference-asset-pension-Social Security space, the individual calculates the utility value of consumption if he or she were to work and the utility value of consumption plus leisure if the individual were to retire either fully or partially. The career job variable refers to whether the individual has the option of working in the career job this period; if not, the decision to work full-time refers to a post-retirement job. In the terminal period, where there is no value to having assets left over, the individual will simply consume all available assets and income. The individual chooses to work or not depending on which choice yields the highest total utility, and the marginal utility of assets is the marginal utility associated with that consumption choice.

The solution moves back to the next to the last period. The individual must again decide whether to work or not and how much to consume, except that this time the consumption decision is not necessarily to consume all available resources. Rather, for each potential consumption decision, there will be a certain amount of assets left over. Using the marginal utility values for the final period, and allowing for the probabilities of rates of returns on these 
assets, the probabilities of changes in the retirement preferences, and the time preference rate, the expected marginal utility of these assets can be calculated. The individual would choose that level of consumption which just matches the marginal utility of a dollar of current consumption with the expected marginal utility of leaving the dollar in assets to be consumed in the future. If necessary, future asset values between the grid points are interpolated. The individual does this calculation both for the case of working and not working for each cell in the career jobretirement preference-asset-pension-Social Security space, and chooses whichever case yields the highest level of utility, including expected future utility from the assets to be carried forward.

This procedure is carried on to period $\mathrm{t}-2, \mathrm{t}-3$, and so on to period 1 , which is presumed to correspond to the age just after the individual finishes school. In effect, the model calculates out a complete contingent decision tree for work and asset accumulation. To simulate the individual, we start with no assets and a random draws of the overall retirement preferences $\varepsilon$ and the utility of partial retirement leisure $\mathrm{V}_{\mathrm{p}}$. The model tells what the work and consumption choices will be, which in turn tells what the assets to be carried into the next period will be. The realized rate of return on those assets determines the level of assets at the beginning of the next period. If the individual retires, a random draw will determine the change in retirement preferences. If the individual chooses to work in the initial period and has a defined contribution pension, the realized rate of return will also determine the increase in the value of the balance in the pension. For the new level of assets and retirement preferences, the individual decides again whether to retire or not and how much to consume. If the individual worked in the career job in the previous period and retires, the amount of potential pension and Social Security benefits (which may not be collectable yet) are determined. The calculations for the remaining periods are done similarly. 
In the estimations and simulations, the model uses a grid with 40 points for assets, 10 for defined contribution balances, 17 for overall retirement preferences, 6 for partial retirement preferences, and 4 each for pensions and Social Security values. The number of calculations each period is related to the product of the number of points for each of these variables, multiplied again by the two categories for the career job variable.

\section{Data sources and the sample.}

The primary data used in this analysis is the Health and Retirement Study (HRS), a panel survey of retirement age respondents and their spouses. The survey started in 1992 with about 7,600 households with at least one individual who was 51 to 61 years old at the time. The households have been surveyed at two year intervals since then; we use information through the 2002 survey. The survey attempts to gather comparable information about both spouses in a couple, and it has matched Social Security and pension records for many respondents. For the estimation and simulation of the model, we extract information on the retirement behavior of the respondents, on the amount of wealth they have accumulated, and on their lifetime resources and incomes.

In the data, individuals working at least 30 hours per week and 1560 hours per year are counted as full-time. Individuals working at least 100 hours per year but no more than 25 hours per week or 1250 hours per year are counted as part time, and individuals not doing any work at all are counted as fully retired. Individuals who fall between full time and part time or between part time and retired are classified on the basis of self reports. This means, for instance, that a teacher working 36 weeks at 35 hours per week (1260 total hours per year) would be counted as full-time if the self reported retirement status was "not retired at all." In order to reduce classification error, all work measurements used in the estimation are taken as of the survey 
dates. We do not try to interpolate the actual work effort to dates between the surveys or before the first survey.

Wealth is measured in the 1992 survey and is used only to get an estimate of the respondent's time preference, which as indicated before is regarded as a fixed effect in the model. Roughly speaking, time preference is taken to be the value for which the observed wealth is consistent with the wealth that would be generated by the model. In this regard, wealth is considered to be wealth that could be used to finance retirement beyond the amounts available from pension and Social Security income, and includes financial wealth, real estate, and business assets. Given the likelihood of measurement error in the wealth of individual respondents, we do not try to use information about the measured increases or decreases in wealth between surveys in the course of estimating the model.

Lifetime resources include a number of components. For about three-quarters of the sample, earnings are reflected in attached Social Security records, adjusted by self reported information for cases over the earnings maximum or for uncovered jobs. The remaining individuals have earnings histories constructed from self reports about current and last jobs, other jobs lasting longer than 5 years, and information about the total number of years worked.

Projecting the future potential earnings that the worker would have on the career job is done by using the experience and tenure coefficients from estimated wage equations. ${ }^{3}$ Projecting the potential earnings for a worker who retires and then returns to full-time work is done by adjusting the tenure coefficients to zero.

3 The wage equation is reported in Appendix Table 1 in Gustman and Steinmeier (2005). This equation suggests a wage drop of about 25 percent for an individual with 20 years of tenure who retires and then tries to return to work. 
Pension information is available for about two-thirds of individuals with pensions. For defined benefit pensions, the annuity is calculated based on the summary plan description provided by the firm. For defined contribution pensions, the contribution amounts are calculated year by year, and the balances are allowed to grow within the model at the stochastic rate of return. Social Security benefit amounts for various potential retirement dates are calculated according to the Social Security rules, assuming the respondents collect benefits when eligible to do so and allowing for the earnings test.

The earnings and pension income of the spouse are calculated and, for the purposes of this model, are taken as exogenous and non-stochastic in order to keep the model computationally tractable. Also taken as exogenous are inheritances and other types of income. Income and capital gains related to assets, of course, are treated as part of the stochastic rate of return to assets.

The prospective distribution of rates of return is based on the historical series calculated by Ibbotson Associates (2002) for various asset classes from 1926 through 2001. To combine these figures into a single rate of return, we look at households in the HRS who had at least some stocks and/or bonds. We rank these households by total financial assets and take the middle 10 percent of the households to assess the distribution of assets among stocks, long-term bonds, and short-term financial instruments. We find that, on average, about 50 percent of these assets are in stocks, 5 percent in bonds, and 45 percent in bank accounts and certificates of deposit. We proxy the returns on these assets by using the Ibbotson returns for large company stocks, longterm government bonds, and treasury bills, respectively. The arithmetic mean of the returns for this weighted average of securities is $5.3 \%$ with a standard deviation of $11 \%$, and the geometric mean is $4.7 \%$. These returns are assumed to be uncorrelated year-to-year, which is 
approximately true in the actual data. Assuming zero correlation has the advantage that it eliminates the necessity to introduce another state variable for the returns to assets.

Appendix Table 1 details the derivation of the estimation sample from the pool of potential observations. We focus on married men in this analysis for two reasons. Since other studies have suggested that it is probably inappropriate to assume the same retirement parameters for men and women, we restrict the analysis to men. Secondly, since many of the unmarried respondents are in fact divorced or widowed, we omit these respondents because the HRS has little information of the earnings of the former spouse. For the same reason, we also omit married men who were divorced or widowed after age 35 and remarried to a new spouse.

The table notes that most of the deletions from the sample come from two sources. The most important is the group that had pension coverage in the most recent full-time job but for whom pension information was not collected from the firms. Since pensions often provide strong incentives to retire at specific dates, the lack of pension information means that we are missing an important influence on retirement. Consequently, we feel it best to omit these observations. The second major omitted group consists of respondents with spotty employment records. This group includes those who have no full-time work after age 50 and also those who work full-time fewer than half the years between age 40 and the last observed year of full-time work. For such respondents, the very concept of retirement is ambiguous, since for much of the time they are not working anyway. There is a third, much less common, group omitted from the sample. These are respondents whose business assets comprise the majority of their wealth. These individuals probably hold these assets for reasons related to the necessity of carrying on a business and not for reasons of acquiring potential retirement assets, and it seems questionable whether it is appropriate to try to infer time preference from the magnitude of these assets. 
The final sample consists of 2,231 respondents for whom we can construct, at least approximately, the details of their earnings and income opportunities, and for whom the model seems appropriate. This is slightly less than half of the number of married men available in the original HRS sample.

\section{Estimation of the model.}

The parameters to be estimated for the model include the consumption parameter $\alpha$, the standard deviation $\sigma_{\varepsilon}$ for the retirement preference variable $\varepsilon$, the correlation $\rho_{\varepsilon}$ of the values of $\varepsilon$ once the individual leaves the main job, the two coefficients $\delta_{0}$ and $\delta_{\mathrm{a}}$ which describe the distribution of $V_{p}$, and the coefficients in the linear term $\beta X_{t}$ which affects retirement preferences. These coefficients include $\beta_{\mathrm{o}}$, the constants, $\beta_{\mathrm{a}}$, the coefficient of age, and $\beta_{\mathrm{h}}$, the coefficient of health.

Each of these parameters have specific implications for the observed pattern of retirement. The estimation procedure in effect uses these implications to help to identify the values of the parameters. $\quad \beta_{0}$ determines the average age of retirement, and $\sigma_{\varepsilon}$ governs the range of retirement ages. $\beta_{\mathrm{a}}$ is perhaps the most important parameter for our purposes, since it determines the sensitivity of retirement to economic incentives. In this model, the individual retires when the utility from retirement grows to more than offset the utility of the extra income from working. If $\beta_{\mathrm{a}}$ is high, the utility of retirement is increasing very rapidly with age, and changes in economic incentives would have to be very large in order to affect the retirement age by much. The opposite is true if $\beta_{\mathrm{a}}$ is relatively low. $\rho_{\varepsilon}$ affects the probability of returning to work after retirement; if $\rho_{\varepsilon}$ is low, then individuals may experience large shifts in retirement preferences after retiring, and a return to work is more likely. $\delta_{0}$ mainly affects the percentage of individuals who partially retire, and $\delta_{\mathrm{a}}$ governs how this percentage changes with age. $\alpha$ 
affects how retirement varies with general lifetime income. If $\alpha$ is near unity, then the marginal utility of income diminishes little at high income levels, and high income workers should retire later in order to reap the benefits of their higher wages. The opposite is true if $\alpha$ is non-trivially negative. Finally, $\beta_{\mathrm{h}}$ reflects the degree to which bad health encourages retirement, over and above its impact through earnings.

To estimate these parameters, we use the Generalized Method of Moments (GMM) method. We choose this method rather than the more common maximum likelihood estimator because it is less sensitive to a relatively small number of cases where the observed result is not very likely given the model. A notable example is someone who retires after 19 years with an employer, when by staying 20 years the individual would be eligible for a substantially higher pension. This could occur because the years of service with the employer are not measured accurately, or because the individual faced some event which caused retirement despite the pension incentives, or for a whole host of other reasons. In the context of the model, this would be a very low probability event, and maximum likelihood would give great weight to increasing the probability if possible. One way to raise this probability is to choose estimates which make individuals insensitive to economic incentives. Such estimates, however, have the difficulty that they cannot reproduce, even approximately, the spikes in retirement observed at ages 62 and 65 .

The GMM estimator begins with a series of moments, which are nothing more that the difference between some observed characteristic of the sample and the expected value of that characteristic implied by the model. One example is the percentage of the sample that is retired during one of the surveys. If the model is approximately valid, the observed value of the characteristic should be close to the expected value implied by the model, and the difference should be fairly small. 
The chosen moments are grouped into a vector $\mathbf{m} .{ }^{4}$ For the present model, the moment vector includes full retirement at all ages between ages 54 and 66 . For ages 55, 58, 60, 62 and 65 , the vector also includes full or partial retirement, full retirement if the observation is in the upper third of lifetime income, full retirement if the observation is in the lower third of lifetime income, and full retirement if the individual is in poor health, and full or partial retirement if the individual is in poor health. The final set of moments in the vector is a measure of the frequency with which individuals return to full-time work in one survey, given that they were fully or partially retired in the previous survey. All in all, we use 43 moments in the vector $\mathbf{m}$.

Generalized method of moments seeks to minimize the quantity

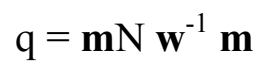

where

$$
\mathbf{w}=\sum_{\mathrm{i}=1}^{\mathrm{n}} \mathbf{m}_{\mathrm{t}} \mathbf{m}_{\mathrm{t}}^{\prime}
$$

If the model is correct, then each moment is a measure of an observed value around its expected value. In the limit, $\mathbf{m}$ should have a multivariate normal distribution. In the expression for $\mathbf{w}$, $\mathbf{m}_{\mathrm{i}}$ is the vector of moments of a single observation, so that $\mathbf{w}$ is essentially an estimate of the variance-covariance matrix of $\mathbf{m}$. $\mathrm{q}$ is thus approximately a quadratic form and, if the model is correct, it should have a $\chi^{2}$ distribution with the degrees of freedom given by the number of moments less the number of parameters being estimated. The variance of the estimates is given by

$$
\operatorname{Var}(\boldsymbol{\theta})=\left[\mathbf{G ~ w}^{-1} \mathbf{G}\right]^{-1}
$$

${ }^{4}$ The notation for the discussion of GMM is taken from Greene (2000) but is similar to the notation in many other econometric texts. 
where $\boldsymbol{\theta}$ is the vector of parameters to be estimated and $\mathbf{G}$ is the derivative of the moments with respect to the parameters.

We note a couple of caveats with regard to the estimation procedure. The first has to do with the time preference parameter, which we mentioned before would be treated as a fixed effect in the estimation. As a result, there is no single estimated parameter for time preference. Rather, for each individual, the value of the time preference parameter is such that, given the values of the other parameters, the resulting value of calculated wealth in 1992 is just equal to the actual value of wealth. In general, high values of wealth are associated with low time preference rate parameters and vice verse, although this relationship may be affected if the individual is expecting high pension or Social Security benefit streams. In some cases, assets are higher than would be expected even at a zero time preference rate; we take this as evidence that the time preference rate is low and assign it a value of zero. At the other extreme, an individual with zero assets is assigned a high enough time preference rate to insure that such an individual consumes all income in every period.

To simplify the calculation of time preference and keep the calculations tractable, we ask what time preference would generate the savings corresponding to the respondent's observed level of assets in 1992, given the expected retirement date and its associated income flows. To do this, we calculate a simplified version of the model with stochastic returns but with labor supply fixed at the expected (or actual) retirement date. The solution of the model is a contingent decision tree with consumption at any age contingent on assets and realized returns. ${ }^{5}$ To get the computed assets at any age, we assume that the individual initially has zero assets. In each year, the assets from the previous year are increased by the observed return that year, and

\footnotetext{
${ }^{5}$ Note that with the path of work effort fixed, consumption no longer depends on $\varepsilon$.
} 
the contingent consumption decision implies the amount of assets that will be carried over into the next year. This process is continued until 1992, when the asset level is observed. The contingent decision tree for the model depends on the individual's time preference rate, and the time preference rate can be adjusted until the calculated assets just match the observed assets.

This procedure is approximate because the uncertainty of future returns will make the future retirement date a bit uncertain, which in turn will make total lifetime earnings uncertain. However, the observed spread of assets, even adjusting for potential lifetime earnings, is so large that it is hard to imagine that uncertainties regarding the ultimate retirement age change the optimal assets by a large amount. Although not completely accurate, this procedure is probably sufficient to distinguish individuals with high time preference, who consume most if not all of their income, from individuals with low time preference, who save considerable funds for retirement unless they expect to have exceptionally large pensions. This approximation allows time preference to be calculated prior to the solution to the rest of the model, which greatly simplifies the computations and helps make the model computationally feasible. Even so, the time preference rate must be recalculated each time the estimation considers a new set of parameters.

The second caveat is in regard to the expected values used to calculate the moments. In a model as complex as the present one, it is very difficult if not impossible to calculate closed form solutions for the expected probability of retirement at a given age or date. Rather, we calculate the expected probabilities based on simulations of the model. For any given set of parameters, including the time preference parameter whose value is calculated as described in the last couple of paragraphs, the complete model may be solved as a contingent decision tree relating the 
consumption and work decisions to the available levels of assets, pensions, Social Security benefits, and whether the individual has previously retired.

We then simulate the model 10,000 times for each observation. For each simulation, we start the individual with zero assets and take a random draw for the unobserved stochastic retirement preference variable $\varepsilon$. For each year, given the assets at the beginning of that year, the consumption and work decisions are given by the contingent decision tree, using the observed values of the rate of return. The retirement distribution is cumulated over the simulations and is used to calculate the moments. More properly, this estimation technique should be called the Generalized Method of Simulated Moments, since we use simulated moments rather than theoretical moments. Since the number of simulations is large, however, the simulated moments should be very good approximations to the theoretical moments, and the resulting estimates should be almost identical to those using theoretical moments.

\section{E. Parameter estimates.}

The coefficients estimated by the simulated GMM procedure are reported in Table 1. The estimated coefficients are all significantly different from zero by conventional standards. Of particular importance, the coefficient of the age variable implies that retirement leisure is increasing in value by 5.4 percent per year. This relatively low value means that economic incentives should be able to have considerable influence on retirement. The autocorrelation coefficient for the leisure preference term is significantly less than unity, which means that individuals can experience changes in their perception of retirement after they begin to experience it. If they find retirement less attractive than anticipated, they may well reverse course and go back to work for a while, at least until the inexorable march of age finally makes 
retirement appealing again. Poor health increases the value of retirement leisure by approximately the same amount as being over seven years older.

The overall fit of the model is measured by the q-statistic. If the model is correct, the departures of the observed moments from their theoretical means should be random, and the qstatistic should be distributed as a $\chi^{2}$ with degrees of freedom equal to the number of moments less the number of parameters. In the present context, there are 43 moments and 8 parameters, so the degrees of freedom are 35. The statistic of 41.56 is well within the bounds of a $\chi^{2}$ with 35 degrees of freedom, which has a 5 percent critical value of 49.80 . This means that, at least among the moments considered in the estimation, there is no evidence that the model does not fit the data well.

A key to understanding the distribution of full and partial retirement with age is in the time preference rates. These rates are quite heterogeneous. Half the population exhibits time preference rates below 5 percent and may be expected to respond relatively strongly to delayed incentives. On the other hand, over a third exhibits time preference rates of 20 percent or greater and may be expected essentially to respond only to incentives which affect current consumption. ${ }^{1}$

Table 2 reports observed retirement outcomes, and simulated retirement outcomes under the current program, with each included individual having the work history actually experienced,

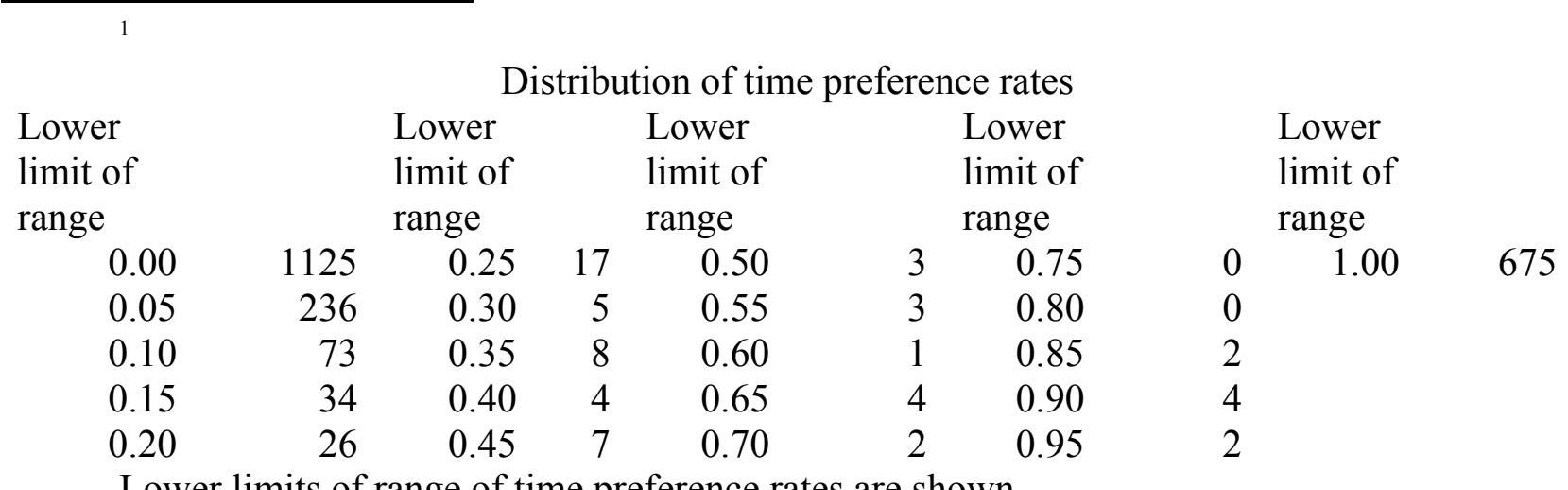

Lower limits of range of time preference rates are shown. 
and reflected in own Social Security earnings record and reported job history. The spike in retirements from full time work at age 62 is approximately the right height, although the spike at age 65 is a couple of percentage points too low. Comparing the flow into full retirement, the spike at 62 is a couple of points low, but the spike at 65 is approximately the right height.

The simulations also do a fairly good job of matching reverse flows. ${ }^{2}$ For example, 3.3 percent of the respondents who were between 54 and 66 in 1994 and 1996 were observed to be working full-time in 1996 and either fully or partially retired in 1994. In the simulations, 3.2 percent of the respondents who were between 54 and 66 in 1994 and 1996 were simulated to be working full-time in 1996 and fully or partially retired in 1994.

\section{Policy Simulations.}

The policies are simulated by altering the budget constraint described above. We begin with the assumption that each person in the Health and Retirement Study is covered by whatever set of Social Security rules governs their benefits. We then ask what happens to retirement outcomes when these rules are changed. In particular, we consider the effects of changing the age of eligibility for early entitlement, the normal retirement age, the earnings test, the level of Social Security benefits and the delayed retirement credit.

\section{A. Baseline Results}

First consider baseline results where retirement outcomes are predicted using the actual rules that will apply to each of the relevant individuals in the Health and Retirement Study.

${ }^{2}$ Reversals from full or partial retirement in one year to full time work in the next.

\begin{tabular}{|l|l|l|l|l|l|}
\hline Year & $1992-1994$ & $1994-1996$ & $1996-1998$ & $1998-2000$ & $2000-2002$ \\
\hline Observed & 2.3 & 3.3 & 3.0 & 3.6 & 2.3 \\
\hline Simulated & 3.9 & 3.2 & 2.7 & 3.1 & 3.3 \\
\hline
\end{tabular}


Columns 2, 4, 6 and 8 of Table 3 show retirement outcomes under actual rules, which include early retirement at age 62 , normal retirement and delayed retirement credit dependent on year of birth, earnings test as the respondent experienced, and payment of 100 percent of scheduled Social Security benefits.

By age 60 , about 60 percent are still working full time, with 50 percent still on their long term job, and about another 10 percent of the population working on a full time job after having retired. Still another 10 percent is partially retired, leaving roughly 30 percent completely retired. By 62 , the fraction working on the main job declines to about one third, with another 7 percent working full time after retiring, and 15 percent partially retired, so that 56 percent of the population is working at all, with a little more than half of them still on their main job. By 65 , only 16 percent are working on their main job, with 7 percent working full time after having retired, and 17 percent partially retired. Thus by 65 as many older men are partially retired as are working on their main job. By age 65,60 percent of the male population is fully retired, out of the labor force entirely. By age 69 , roughly 8 percent are working full time on their main job, 8 percent are working full time after having retired, and 17 percent are partially retired.

Table 4, columns $2,4,6,8$ and 10 show a number of flows among various retirement states. With four states in each year, at each year of age there are 16 different flows. For brevity, we highlight only five of them, most combining more than one flow. The outstanding flow in column 2 is the net flow out of full time work (flow out minus flow in) at age 62, where about 15 percent of the population leaves full time work upon becoming eligible for Social Security benefits. The net flow into full retirement as shown in column 4 is about 10 percent. There is a smooth increase with age in the percentage newly returning to full time work, ranging between 2 and 4 percent of the population. The percent flowing into part time work is of the 
same order of magnitude, and is shown in column 8 . There is a spike in the flow into part time work at age 62 , with 8.7 percent of the population entering part time work at 62 . As can be seen by comparing columns 8 and 10, until age 65 , most of those entering part time work come from full employment. After age 65, more than half of those entering part time work come from full retirement.

It is also of interest to compare the flows in Table 4 with the corresponding stocks in Table 3 . From age 62 on, the fraction partially retired in Table 3 is roughly 15 percent to 17 percent. After age 62, the flow into partial retirement from Table 4 is about 4 percentage points each year. This suggests an average duration of partial retirement of about four years.

\section{B. Effects of an Early Entitlement Age of 64}

Tables 3 and 4 also show retirement outcomes when the early entitlement age is 64 . The relevant figures appear in the odd numbered columns beginning with column 3 in each table, and are labeled $\mathrm{ER}=64$. Comparing columns 2 and 3 of Table 3 , the effect of increasing the early entitlement age to 64 is apparent. With the older early entitlement age, about 5 percent more of the population continues to work full time at their main job at 62 and 63 than would otherwise. In addition, comparing columns 5 and 4 at age 62 , with the older early entitlement age another 4.5 percent of the male population works full time after having retired, as does another 4 percent at age 63. Partial retirement is reduced at ages 62 and 63 by about 3 percentage points when the early entitlement age is 64 . Overall, complete retirements are about 6 percentage points lower at 62 and 63 when the early retirement age is higher. From age 64 on, the percent completely retired is about two percentage points higher in each year when the early entitlement age is 62 rather than 64 , with the difference coming in small fractions from all three remaining categories. 
As can be seen in Table 4, the spike in flows out of full time work, and into full retirement, shifts very clearly from 62 to 64 when the early entitlement age is higher. In addition, from columns 8 and 9, there is an obvious shift in the spike of those newly flowing into part time work, with the 8.7 percent spike at age 62 halving when the early entitlement age is increased, while the spike at age 64 doubles to 8.1 percent of the population newly entering partial retirement.

\section{Effects of Varying the Normal Retirement Age}

Given the birth years of the HRS cohort, most of them faced an age 65 normal retirement age under Social Security. Consequently, there are almost no differences in retirement outcomes when Table 5 compares actual ages of normal retirement to the effect of a normal retirement age of 65 . When the normal retirement age is simulated to be 67 , the fraction at full time work on their main job is decreased by one or two percentage points between the ages of 62 and 64, and is increased by about two percentage points at ages 65 and 66, with the gap decreasing thereafter. When the retirement age is 67 rather than 65 , there is a lower reward to postponed retirement for those who would otherwise retire at or just after the early entitlement age, so a few are encouraged to retire earlier than they would have had the normal retirement age remained at 65 . From 65 on, income from Social Security is reduced once the normal retirement age is raised to 67. There is a lower wealth effect from Social Security at the higher retirement age, encouraging a few to remain at full time work. Similar effects are found for the percent in full time work after retiring. Starting at age 62, a higher normal retirement age is associated with an increase in the share in part time work from half a percent to two percent. Taking these three effects into account, the percent fully retired is about two percentage points higher at ages 62 and 63 with a normal retirement age of 67 , and is 2 to 4 percentage points lower from age 64 on. 
Table 6 shows the related flows. The major difference in these flows is at age 62 , where the percent retiring from full time work, and the percent retiring completely, are about 2 percentage points higher at age 62 with normal retirement at 67 instead of 65 . At 64 and 65 , the flows into retirement are higher with normal retirement age at 65 , commensurate with the differences in the stocks of employed and retired discussed in the context of Table 5.

\section{Effects of Varying the Earnings Test}

According to Table 7, there is only a minor effect of changing the earnings test. From age 65 on, there is about a half a percentage point increase in the probability of working on the main job from abolishing the earnings test after age 65. Abolishing the earnings test altogether increases the probability of work on the main job by another one half to one percentage point. Abolishing the earnings test after age 65 increases the probability of returning to full time work at 65 and after by about 1 percentage point per year, while reducing the probability of partial retirement by a similar amount. Abolishing the earnings test entirely, compared to leaving the earnings test in force before normal retirement age, increases full retirement at 62 and 63 by about one percentage point. The changes in retirement flows shown in Table 8 remain similarly small.

\section{E. Effects of Reducing Benefits to $75 \%$ of the Promised Level}

There are large wealth effects from reducing Social Security benefits to 75 percent of their promised level. If there were no changes in funding, this is the approximate amount benefits would have to be reduced to when the trust fund runs out. The probability of remaining on the main job is higher when benefits are reduced for those in their sixties, with the difference ranging from 3 to 5 percentage points for those ages 62 and older. At each year of age, the probability of remaining at full time work after having retired is increased by an additional 1 
percentage point when benefits are cut. There is little difference in the fraction partially retired, so the probability of being fully retired is reduced by 4 to 6 percentage points when benefits are reduced by a quarter. In terms of the corresponding flows, the first four columns of Table 10 show that the spikes in retirement rates out of full time work, and flows into full retirement, at both age 62 and at age 64, are reduced by about 2 percentage points when benefits are lower.

\section{F. Effects of Increasing the Delayed Retirement Credit}

According to the findings in Table 11, when the delayed retirement credit is 8 percent rather than 3 percent, the probability of remaining in the main job is 1 or 2 percentage points higher in each year after reaching 65 . There is a corresponding difference of one half to one and a half percentage points in the probability of working full time after having returned from retirement. The probability of partial retirement is a quarter to half a percentage point lower after reaching 65 with the higher delayed retirement credit, so the additional work is taking the form of participation in the full time labor force. Altogether then, the probability of complete retirement is reduced by 1 to 3 percentage points for those 65 and above when the delayed retirement credit is increased from 3 to 8 percentage points.

\section{Conclusions.}

We have used a dynamic, stochastic econometric model of retirement estimated with data from the Health and Retirement Study to analyze the effects of various features of the Social Security system on a rich array of retirement outcomes, as well as saving. The model allows for partial retirement, reversals of flows from states of lesser to greater work, and stochastic returns to assets. We have consider the effects of changes in the age of eligibility for early entitlement, the normal retirement age, the earnings test, the level of Social Security benefits and of changes in the delayed retirement credit. Outcomes considered include the various retirement outcomes 
and the flows from one retirement state to another. We have also analyzed the effects of the various features of the current Social Security benefit structure on the flows among the states of retirement, partial retirement and full time work both on the job held for a long term, as well as full time jobs returned to after fully or partially retiring.

The largest effects of the policies examined are from increasing the early entitlement age from 62 to 64 and reducing benefits to 75 percent of their promised levels. With the older early entitlement age, about 5 percent more of the population continues to work full time at their main job at 62 and 63 than would otherwise. In addition, another 4.5 percent of the male population works full time after having retired, as does another 4 percent at age 63. Partial retirement is reduced at ages 62 and 63 by about 3 percentage points when the early entitlement age is 64 . Overall, complete retirements are about 6 percentage points lower at 62 and 63 when the early retirement age is higher. From age 64 on, the percent completely retired is about two percentage points lower in each year when the early entitlement age is 64 rather than 62 , with the difference coming in small fractions from all three remaining categories.

The effects of reducing promised Social Security benefits by about a quarter are also large. The probability of remaining on the main job is higher for those in their sixties, with the difference ranging from 3 to 5 percentage points for those ages 62 and older. At each year of age, an additional 1 percentage point will be in full time work after having retired. There is little difference in the fraction partially retired, so the probability of being fully retired is reduced by 4 to 6 percentage points when benefits are reduced by a quarter. 


\section{References}

Coile, Courtney, Peter Diamond, Jonathan Gruber and Alain Jousten. 2002. "Delays in Claiming Social Security Benefits". Journal of Public Economics 84(3): 357-385.

French, Eric. 2005. "The Effects of Health, Wealth and Wages on Labor Supply and Retirement Behavior”. Review of Economic Studies 72: 395-427.

Greene, William H. 2000. Econometric Analysis, Fourth Edition. Upper Saddle River: Prentice Hall.

Gustman, Alan L. and Thomas L. Steinmeier. "Modeling the Retirement Process for Policy Evaluation and Research". Monthly Labor Review 107(7): 26-33. . 1986. "A Structural Retirement Model." Econometrica 54(3): 555584. . 2000. "Retirement Outcomes In The Health and Retirement

Study". Social Security Bulletin, Perspectives 63(4): 3-17. . 2002a. "Retirement and Wealth". Social Security Bulletin, 2001/2002 64(2): 1-26. . 2002b. "Retirement and the Stock Market Bubble". NBER

Working Paper 9404, December. . 2005. "The Social Security Early Retirement Age In A Structural

Model of Retirement and Wealth." Journal of Public Economics 89(2-3): 441-463. Ibbotson Associates. 2002. Valuation Edition 2002 Yearbook. Chicago: Ibbotson Associates. 
Ippolito, Richard A, 1997, Pension Plans and Employee Performance: Evidence, Analysis, and Policy, Chicago: University of Chicago Press.

Maestas, Nicole. 2005. "Back to Work: Expectations and Realizations of Work after Retirement," RAND Working Paper, September.

Song, Jae G. and Joyce Manchester. 2006. "New Evidence on Earnings and Benefit Claims Following Changes in the Retirement Earnings Test in 2000". U.S. Social Security Administration, Office of Policy. ORES Working Paper No. 107, June.

Rust, John and Christopher Phalen. 1997. "How Social Security and Medicare Affect Retirement”. Econometrica 65(4):781-831.

van der Klaauw, Wilbert and Kenneth I. Wolpin. 2006. "Social Security and the Retirement and Savings Behavior of Low Income Households". Mimeo. 
Table 1

Estimated Results

\begin{tabular}{|c|c|c|c|}
\hline Symbol & Description & \multicolumn{2}{|c|}{$\begin{array}{c}\text { Coefficient } \\
\text { Value }\end{array}$} \\
\hline \multirow[t]{2}{*}{$\alpha$} & Consumption parameter & -0.14 & 3.07 \\
\hline & Parameters in $\beta$ & & \\
\hline$\beta_{0}$ & Constant & -9.61 & 390.05 \\
\hline$\beta_{\mathrm{a}}$ & Coefficient of Age ${ }^{a}$ & 0.054 & 11.39 \\
\hline$\beta_{\mathrm{h}}$ & Coefficient of Health ${ }^{\mathrm{c}}$ & 7.23 & 16.53 \\
\hline \multirow[t]{2}{*}{$\rho_{\varepsilon}$} & Correlation of $\varepsilon$ after retirement & 0.84 & 22.96 \\
\hline & Parameters in $\delta$ & & \\
\hline$\delta_{0}$ & Constant & -3.71 & 7.93 \\
\hline$\delta_{\mathrm{a}}$ & Coefficient of Age $\mathrm{b}^{\mathrm{b}}$ & 0.21 & 1.88 \\
\hline$\sigma_{\varepsilon}$ & Standard Deviation of $\varepsilon^{c}$ & 7.98 & 13.98 \\
\hline & q value & & 41.5641 \\
\hline & Number of observations & & 2231 \\
\hline
\end{tabular}


Several variables are differenced from their approximate means in the sample in order to facilitate estimation. They are:

${ }^{\mathrm{a}}$ The actual variable is age -62 .

b The actual variable is age -65 .

c These coefficients are all relative to the age coefficient, again to facilitate estimation. 
Table 2: Observed and Projected Retirement Percentages

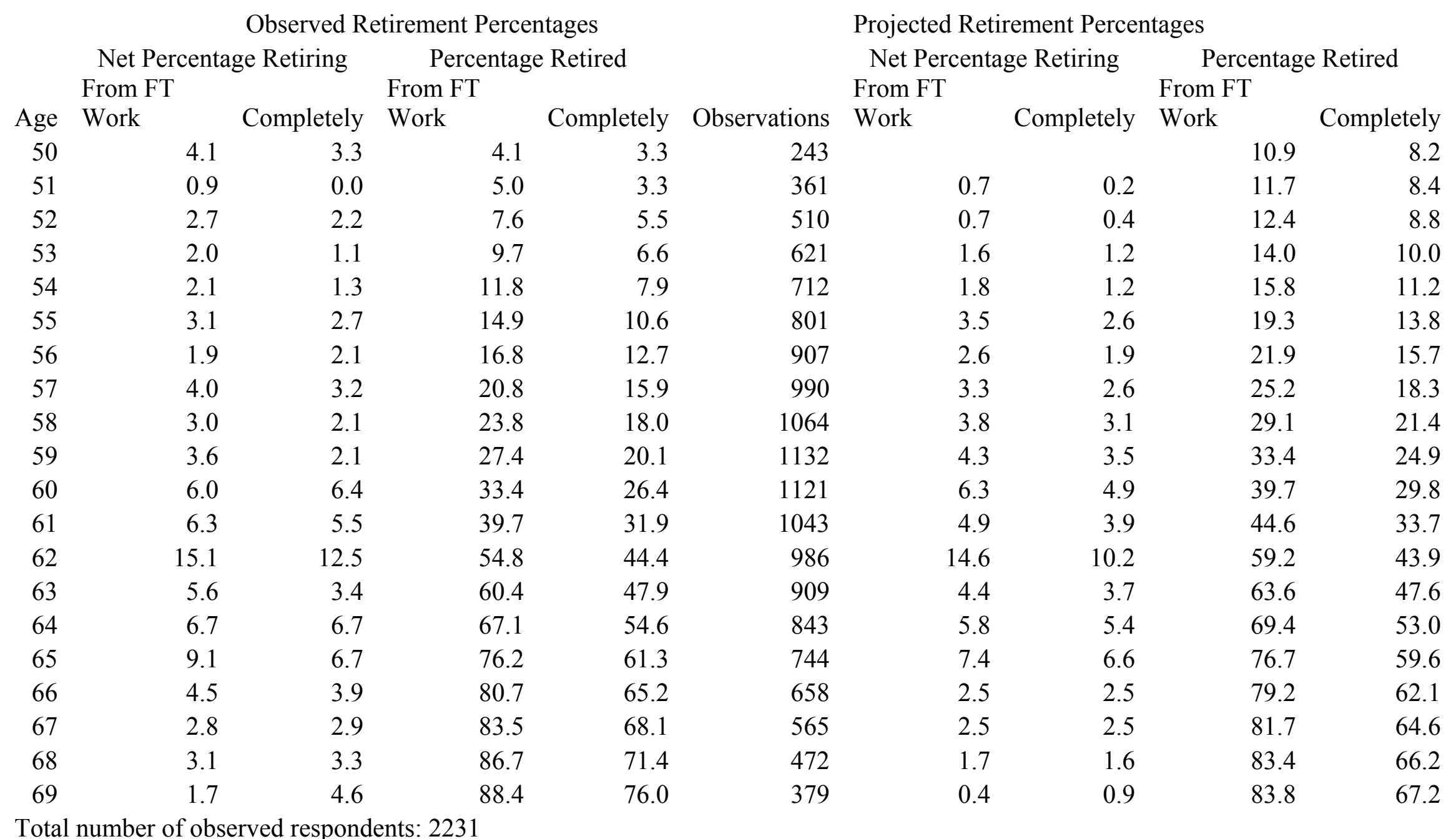


Table 3: Effects of Early Retirement Ages of 62 vs. 64 on the Probability of Falling in Various Retirement States

(Assumes Actual Normal Retirement Age, Actual Earnings Test, 100 Percent of Formula Benefits and Actual Delayed Retirement Credit)

\begin{tabular}{|c|c|c|c|c|c|c|c|c|}
\hline & \multicolumn{2}{|c|}{ Percent in Main Job } & \multicolumn{2}{|c|}{$\begin{array}{l}\text { Percent in Full Time Work } \\
\text { After Retiring }\end{array}$} & \multicolumn{2}{|c|}{ Percent in Part Time Work } & \multicolumn{2}{|c|}{ Percent Completely Retired } \\
\hline Age & $\mathrm{ER}=62$ & $E R=64$ & $\mathrm{ER}=62$ & $\mathrm{ER}=64$ & $\mathrm{ER}=62$ & $\mathrm{ER}=64$ & $\mathrm{ER}=62$ & $\mathrm{ER}=64$ \\
\hline & & & & & & & & \\
\hline 55 & 74.1 & 74.3 & 6.6 & 6.6 & 5.5 & 5.4 & 13.8 & 13.6 \\
\hline 60 & 50.4 & 51.2 & 9.9 & 10.1 & 9.9 & 9.8 & 29.8 & 28.9 \\
\hline 61 & 44.7 & 45.3 & 10.6 & 10.9 & 10.9 & 10.9 & 33.7 & 32.9 \\
\hline 62 & 33.4 & 38.5 & 7.4 & 11.9 & 15.3 & 12.3 & 43.9 & 37.4 \\
\hline 63 & 28.5 & 33.5 & 7.9 & 11.9 & 16 & 13.7 & 47.6 & 41.0 \\
\hline 64 & 23.0 & 24.0 & 7.6 & 8.0 & 16.4 & 16.3 & 53.0 & 51.6 \\
\hline 65 & 15.9 & 17.6 & 7.4 & 7.8 & 17.1 & 17.3 & 59.6 & 57.3 \\
\hline 66 & 13.0 & 14.3 & 7.8 & 8.2 & 17.1 & 17.5 & 62.1 & 60.0 \\
\hline 67 & 10.8 & 11.9 & 7.5 & 7.9 & 17 & 17.4 & 64.6 & 62.8 \\
\hline 68 & 9.2 & 10.1 & 7.4 & 7.8 & 17.1 & 17.4 & 66.2 & 64.8 \\
\hline 69 & 7.9 & 8.6 & 8.3 & 8.7 & 16.6 & 16.9 & 67.2 & 65.8 \\
\hline
\end{tabular}


Table 4: Effects of Early Retirement Ages of 62 vs. 64 on Selected Flows and Flows Among Various Retirement States (Assumes Actual Normal Retirement Age, Actual Earnings Test, 100 Percent of Formula Benefits and Actual Delayed Retirement Credit)

\begin{tabular}{|c|c|c|c|c|c|c|c|c|c|c|}
\hline \multirow[b]{2}{*}{ Age } & \multicolumn{2}{|c|}{$\begin{array}{l}\text { Net Percent } \\
\text { Retiring from } \\
\text { Full Time Work }\end{array}$} & \multicolumn{2}{|c|}{$\begin{array}{l}\text { Net Percent } \\
\text { Completely Retiring }\end{array}$} & \multicolumn{2}{|c|}{$\begin{array}{l}\text { Percent Newly } \\
\text { Returned to Full } \\
\text { Time Work }\end{array}$} & \multicolumn{2}{|c|}{$\begin{array}{l}\text { Percent Newly in } \\
\text { Part Time Work }\end{array}$} & \multicolumn{2}{|c|}{$\begin{array}{l}\text { Percent Newly } \\
\text { Returned to Part }\end{array}$} \\
\hline & $\mathrm{ER}=62$ & $E R=64$ & $\mathrm{ER}=62$ & $\mathrm{ER}=64$ & $\mathrm{ER}=62$ & $E R=64$ & $\mathrm{ER}=62$ & $\mathrm{ER}=64$ & $\mathrm{ER}=62$ & $\mathrm{ER}=64$ \\
\hline 55 & 3.5 & 3.5 & 2.6 & 2.6 & 2.0 & 2.0 & 2.6 & 2.6 & 0.7 & 0.7 \\
\hline 60 & 6.3 & 5.9 & 4.9 & 4.6 & 2.9 & 2.9 & 3.7 & 3.7 & 1.1 & 1.1 \\
\hline 61 & 4.9 & 5.0 & 3.9 & 4.0 & 3.2 & 3.3 & 3.7 & 3.7 & 1.3 & 1.2 \\
\hline 62 & 14.6 & 5.9 & 10.2 & 4.5 & 2.8 & 3.8 & 8.7 & 4.3 & 1.0 & 1.4 \\
\hline 63 & 4.4 & 5.0 & 3.7 & 3.6 & 3.2 & 3.5 & 4.1 & 4.3 & 1.9 & 1.4 \\
\hline 64 & 5.8 & 13.3 & 5.4 & 10.7 & 3.0 & 3.0 & 4.1 & 8.0 & 1.9 & 1.2 \\
\hline 65 & 7.4 & 6.7 & 6.6 & 5.7 & 3.3 & 3.4 & 4.8 & 4.9 & 2.3 & 2.4 \\
\hline 66 & 2.5 & 2.8 & 2.5 & 2.7 & 3.6 & 3.8 & 4.0 & 4.2 & 2.4 & 2.4 \\
\hline 67 & 2.5 & 2.7 & 2.5 & 2.9 & 3.3 & 3.4 & 3.8 & 3.9 & 2.3 & 2.3 \\
\hline 68 & 1.7 & 2.0 & 1.6 & 1.9 & 3.4 & 3.5 & 3.6 & 3.7 & 2.3 & 2.3 \\
\hline 69 & 0.4 & 0.5 & 0.9 & 1.1 & 4.1 & 4.2 & 3.3 & 3.4 & 2.3 & 2.3 \\
\hline
\end{tabular}


Table 5: Effects of Different Normal Retirement Ages, Actual vs. Ages 65 and 67, on the Probability of Falling in Various Retirement States (Assumes Actual Early Entitlement Age, Actual Earnings Test, 100 Percent of Formula Benefits and Actual Delayed Retirement Credit)

\begin{tabular}{|c|c|c|c|c|c|c|c|c|c|c|c|c|}
\hline \multirow[b]{2}{*}{ Age } & \multicolumn{3}{|c|}{ Percent in Main Job } & \multicolumn{3}{|c|}{$\begin{array}{l}\text { Percent in Full Time Work } \\
\text { After Retiring }\end{array}$} & \multicolumn{3}{|c|}{ Percent in Part Time Work } & \multicolumn{3}{|c|}{ Percent Completely Retired } \\
\hline & Actual & $\mathrm{NR}=65$ & $\mathrm{NR}=67$ & Actual & $\mathrm{NR}=65$ & $\mathrm{NR}=67$ & Actual & $\mathrm{NR}=65$ & $\mathrm{NR}=67$ & Actual & $\mathrm{NR}=65$ & $\mathrm{NR}=67$ \\
\hline & & & & & & & & & & & & \\
\hline 55 & 74.1 & 74.1 & 74.2 & 6.6 & 6.6 & 6.6 & 5.5 & 5.5 & 5.5 & 13.8 & 13.9 & 13.7 \\
\hline 60 & 50.4 & 50.3 & 50.9 & 9.9 & 9.9 & 10.0 & 9.9 & 9.9 & 9.9 & 29.8 & 29.9 & 29.2 \\
\hline 61 & 44.7 & 44.7 & 45.0 & 10.6 & 10.6 & 10.8 & 10.9 & 10.9 & 10.9 & 33.7 & 33.7 & 33.2 \\
\hline 62 & 33.4 & 33.6 & 32.1 & 7.4 & 7.6 & 7.0 & 15.3 & 15.3 & 15.9 & 43.9 & 43.6 & 45.0 \\
\hline 63 & 28.5 & 28.5 & 26.6 & 7.9 & 7.8 & 7.4 & 16.0 & 15.9 & 16.7 & 47.6 & 47.8 & 49.3 \\
\hline 64 & 23.0 & 23.0 & 22.7 & 7.6 & 7.5 & 8.9 & 16.4 & 16.3 & 17.1 & 53.0 & 53.3 & 51.3 \\
\hline 65 & 15.9 & 15.7 & 17.9 & 7.4 & 7.5 & 8.6 & 17.1 & 16.9 & 17.7 & 59.6 & 59.8 & 55.8 \\
\hline 66 & 13.0 & 12.9 & 14.7 & 7.8 & 7.7 & 8.4 & 17.1 & 17.0 & 17.8 & 62.1 & 62.4 & 59.0 \\
\hline 67 & 10.8 & 10.7 & 11.7 & 7.5 & 7.4 & 8.2 & 17.0 & 16.9 & 17.6 & 64.6 & 64.9 & 62.5 \\
\hline 68 & 9.2 & 9.1 & 9.9 & 7.4 & 7.3 & 7.9 & 17.1 & 17.0 & 17.7 & 66.2 & 66.5 & 64.4 \\
\hline 69 & 7.9 & 7.9 & 8.5 & 8.3 & 8.2 & 8.9 & 16.6 & 16.5 & 17.2 & 67.2 & 67.4 & 65.4 \\
\hline
\end{tabular}


Table 6: Effects of Different Normal Retirement Ages, Actual vs. Ages 65 and 67, on Selected Flows Among Various Retirement States (Assumes Actual Early Entitlement Age, Actual Earnings Test, 100 Percent of Formula Benefits and Actual Delayed Retirement Credit)

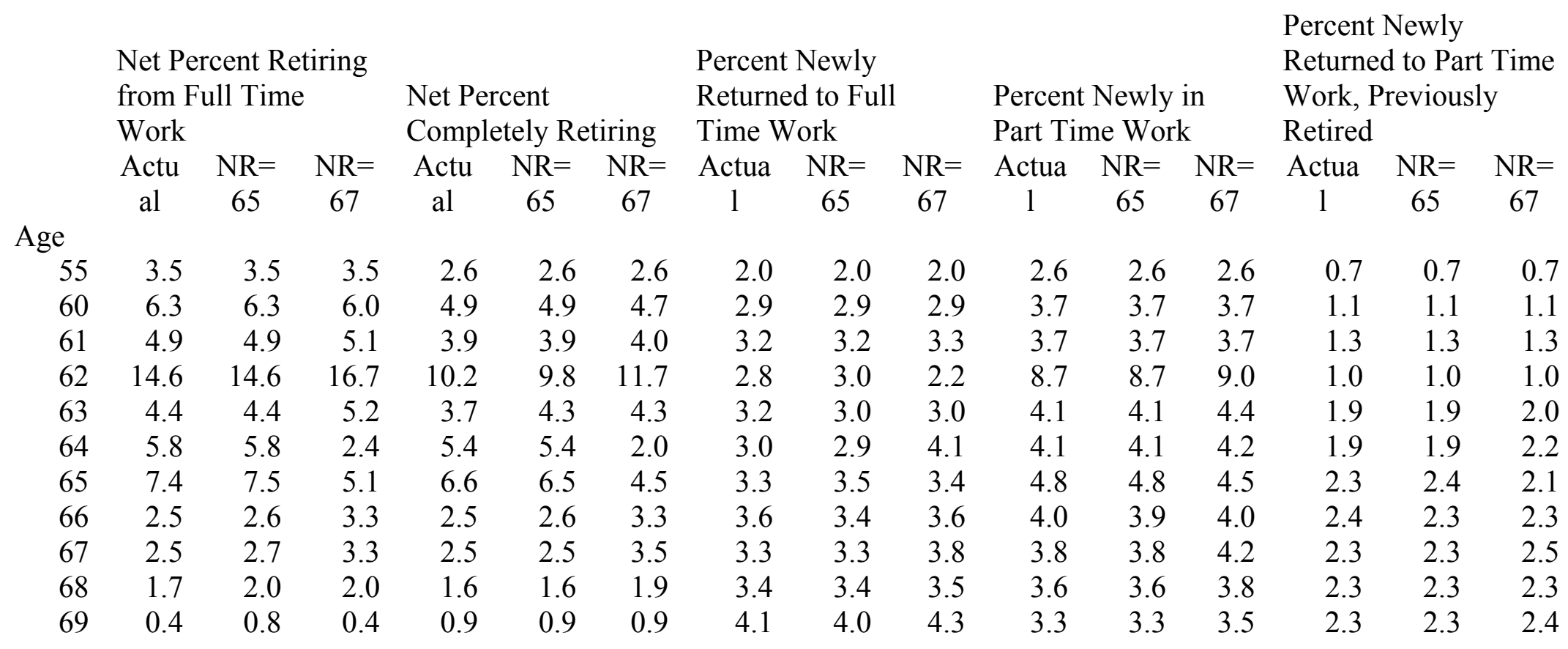


Table 7: Effects of Different Earnings Test Rules, Actual, All Years, Before NR, No Test, on the Probability of Falling in Various Retirement States

(Assumes Actual Early Entitlement Age, Actual Normal Retirement Age, 100 Percent of Formula Benefits and Actual Delayed Retirement Credit)

\begin{tabular}{|c|c|c|c|c|c|c|c|c|c|c|c|c|c|c|c|c|}
\hline \multirow[b]{2}{*}{ Age } & \multicolumn{4}{|c|}{ Percent in Main Job } & \multicolumn{4}{|c|}{$\begin{array}{l}\text { Percent in Full Time Work } \\
\text { After Retiring }\end{array}$} & \multicolumn{4}{|c|}{ Percent in Part Time Work } & \multicolumn{4}{|c|}{ Percent Completely Retired } \\
\hline & $\begin{array}{l}\text { Ac- } \\
\text { tual }\end{array}$ & $\begin{array}{l}\text { All } \\
\text { Yrs }\end{array}$ & $\begin{array}{l}\text { Bef. } \\
\text { NR }\end{array}$ & $\begin{array}{l}\text { No } \\
\text { ET }\end{array}$ & $\begin{array}{l}\text { Ac- } \\
\text { tual }\end{array}$ & $\begin{array}{l}\text { All } \\
\text { Yrs }\end{array}$ & $\begin{array}{l}\text { Bef. } \\
\text { NR }\end{array}$ & $\begin{array}{l}\text { No } \\
\text { ET }\end{array}$ & $\begin{array}{l}\text { Ac- } \\
\text { tual }\end{array}$ & $\begin{array}{l}\text { All } \\
\text { Yrs }\end{array}$ & $\begin{array}{l}\text { Bef. } \\
\text { NR }\end{array}$ & $\begin{array}{l}\text { No } \\
\text { ET }\end{array}$ & $\begin{array}{l}\text { Ac- } \\
\text { tual }\end{array}$ & $\begin{array}{l}\text { All } \\
\text { Yrs }\end{array}$ & $\begin{array}{l}\text { Bef. } \\
\text { NR }\end{array}$ & $\begin{array}{l}\text { No } \\
\text { ET }\end{array}$ \\
\hline 55 & 74.1 & 74.1 & 74.1 & 74.2 & 6.6 & 6.6 & 6.6 & 6.6 & 5.5 & 5.5 & 5.5 & 5.5 & 13.8 & 13.9 & 13.8 & 13.8 \\
\hline 60 & 50.4 & 50.3 & 50.4 & 50.5 & 9.9 & 9.9 & 9.9 & 9.9 & 9.9 & 9.9 & 9.9 & 9.9 & 29.8 & 29.8 & 29.8 & 29.7 \\
\hline 61 & 44.7 & 44.7 & 44.7 & 44.6 & 10.6 & 10.7 & 10.6 & 10.6 & 10.9 & 11.0 & 10.9 & 11.0 & 33.7 & 33.7 & 33.7 & 33.7 \\
\hline 62 & 33.4 & 33.3 & 33.4 & 33.7 & 7.4 & 7.4 & 7.4 & 7.8 & 15.3 & 15.4 & 15.4 & 13.7 & 43.9 & 43.9 & 43.9 & 44.8 \\
\hline 63 & 28.5 & 28.4 & 28.5 & 28.0 & 7.9 & 7.9 & 7.9 & 8.2 & 16.0 & 16.0 & 16.0 & 14.5 & 47.6 & 47.7 & 47.6 & 49.2 \\
\hline 64 & 23.0 & 22.9 & 23.0 & 22.7 & 7.6 & 7.6 & 7.5 & 8.3 & 16.4 & 16.5 & 16.4 & 15.2 & 53.0 & 53.0 & 53.1 & 53.8 \\
\hline 65 & 15.9 & 15.8 & 16.5 & 17.5 & 7.4 & 7.2 & 8.4 & 8.4 & 17.1 & 17.5 & 16.4 & 16.0 & 59.6 & 59.6 & 58.7 & 58.1 \\
\hline 66 & 13.0 & 12.9 & 13.5 & 14.4 & 7.8 & 7.4 & 8.4 & 8.5 & 17.1 & 17.6 & 16.6 & 16.4 & 62.1 & 62.1 & 61.5 & 60.7 \\
\hline 67 & 10.8 & 10.6 & 11.3 & 12.0 & 7.5 & 7.0 & 8.0 & 8.2 & 17.0 & 17.5 & 16.7 & 16.6 & 64.6 & 64.9 & 64.0 & 63.2 \\
\hline 68 & 9.2 & 8.9 & 9.6 & 10.2 & 7.4 & 6.7 & 7.9 & 8.2 & 17.1 & 17.6 & 16.8 & 16.8 & 66.2 & 66.8 & 65.6 & 64.8 \\
\hline 69 & 7.9 & 7.6 & 8.3 & 8.8 & 8.3 & 7.2 & 8.7 & 9.1 & 16.6 & 17.1 & 16.4 & 16.4 & 67.2 & 68.1 & 66.6 & 65.8 \\
\hline
\end{tabular}


Table 8: Effects of Different Earnings Test Rules, Actual, All Years, Before NR, No Test, on Selected Flows Among Various Retirement States (Assumes Actual Early Entitlement Age, Actual Normal Retirement Age, 100 Percent of Formula Benefits and Actual Delayed Retirement Credit)

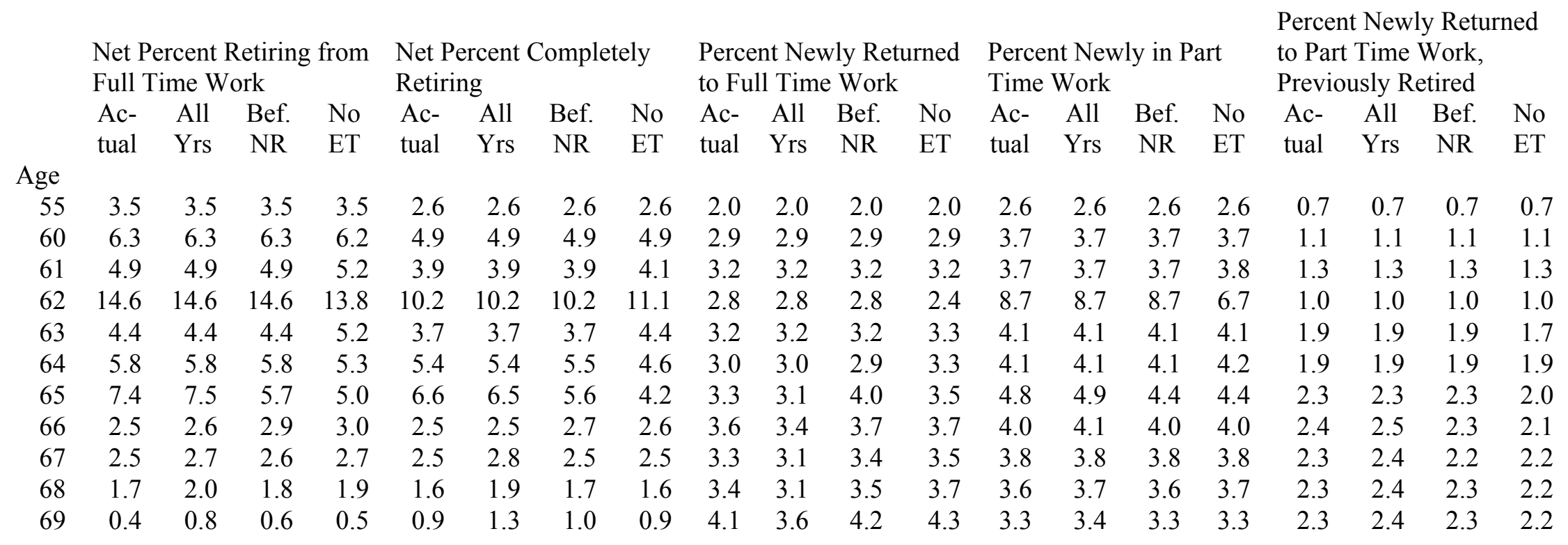


Table 9: Effects of $100 \%$ vs. $75 \%$ of Promised Benefit on the Probability of Falling in Various Retirement States (Assumes Actual Early and Normal Retirement Age, Actual Earnings Test and Actual Delayed Retirement Credit)

\begin{tabular}{|c|c|c|c|c|c|c|c|c|}
\hline & \multicolumn{2}{|c|}{ Percent in Main Job } & \multicolumn{2}{|c|}{$\begin{array}{l}\text { Percent in Full Time Work } \\
\text { After Retiring }\end{array}$} & \multicolumn{2}{|c|}{ Percent in Part Time Work } & \multicolumn{2}{|c|}{ Percent Completely Retired } \\
\hline Age & $\begin{array}{l}100 \% \text { of } \\
\text { Benefit }\end{array}$ & $\begin{array}{l}75 \% \text { of } \\
\text { Benefit }\end{array}$ & $\begin{array}{l}100 \% \text { of } \\
\text { Benefit }\end{array}$ & $\begin{array}{l}75 \% \text { of } \\
\text { Benefit }\end{array}$ & $\begin{array}{l}100 \% \text { of } \\
\text { Benefit }\end{array}$ & $\begin{array}{l}75 \% \text { of } \\
\text { Benefit }\end{array}$ & $\begin{array}{l}100 \% \text { of } \\
\text { Benefit }\end{array}$ & $\begin{array}{l}75 \% \text { of } \\
\text { Benefit }\end{array}$ \\
\hline 55 & 741 & 745 & 66 & 66 & 55 & 54 & 120 & 125 \\
\hline 60 & 504 & 520 & 99 & 101 & 99 & 97 & 298 & 282 \\
\hline 61 & 44.7 & 46.5 & 10.6 & 10.8 & 10.9 & 10.7 & 33.7 & 31.9 \\
\hline 62 & 33.4 & 36.9 & 7.4 & 8.2 & 15.3 & 14.9 & 43.9 & 40.0 \\
\hline 63 & 28.5 & 32.0 & 7.9 & 8.7 & 16.0 & 15.8 & 47.6 & 43.5 \\
\hline 64 & 23.0 & 26.7 & 7.6 & 8.5 & 16.4 & 16.5 & 53.0 & 48.2 \\
\hline 65 & 15.9 & 20.9 & 7.4 & 8.4 & 17.1 & 17.1 & 59.6 & $\overline{53.6}$ \\
\hline 66 & 13.0 & 17.8 & 7.8 & 8.7 & 17.1 & 17.2 & 62.1 & 56.2 \\
\hline 67 & 10.8 & 15.2 & 7.5 & 8.4 & 17.0 & 17.3 & 64.6 & 59.0 \\
\hline 68 & 9.2 & 13.2 & 7.4 & 8.4 & 17.1 & 17.6 & 66.2 & 60.8 \\
\hline 69 & 7.9 & 11.5 & 8.3 & 9.6 & 16.6 & 17.1 & 67.2 & 61.8 \\
\hline
\end{tabular}


Table 10: Effects of $100 \%$ vs. $75 \%$ of Promised Benefit on Selected Flows Among Various Retirement States (Assumes Actual Early and Normal Retirement Age, Actual Earnings Test and Actual Delayed Retirement Credit)

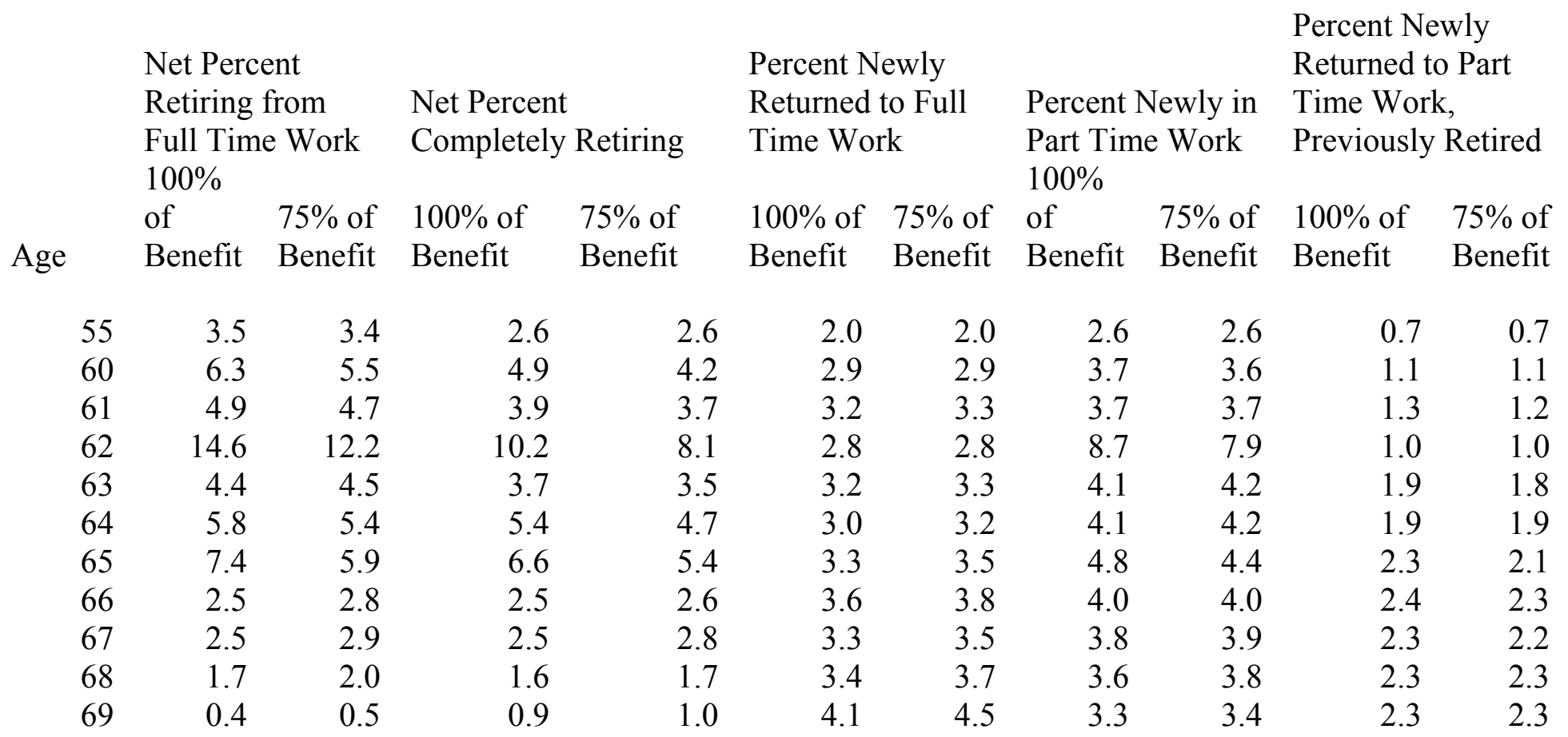


Table 11: Effects of Different Delayed Retirement Credits, Actual vs. 3\% vs. 8\%, on the Probability of Falling in Various Retirement States (Assumes Actual Early and Normal Retirement Ages, Actual Earnings Test and 100 Percent of Formula Benefits)

\begin{tabular}{|c|c|c|c|c|c|c|c|c|c|c|c|c|}
\hline \multirow[b]{2}{*}{ Age } & \multicolumn{3}{|c|}{ Percent in Main Job } & \multicolumn{3}{|c|}{$\begin{array}{l}\text { Percent in Full Time Work } \\
\text { After Retiring }\end{array}$} & \multicolumn{3}{|c|}{ Percent in Part Time Work } & \multicolumn{3}{|c|}{ Percent Completely Retired } \\
\hline & Actual & $\begin{array}{c}\mathrm{DRC}= \\
3 \%\end{array}$ & $\begin{array}{c}\mathrm{DRC}= \\
8 \%\end{array}$ & Actual & $\begin{array}{c}\mathrm{DRC}= \\
3 \%\end{array}$ & $\begin{array}{c}\mathrm{DRC}= \\
8 \%\end{array}$ & Actual & $\begin{array}{c}\mathrm{DRC}= \\
3 \%\end{array}$ & $\begin{array}{c}\mathrm{DRC}= \\
8 \%\end{array}$ & Actual & $\begin{array}{c}\mathrm{DRC}= \\
3 \%\end{array}$ & $\begin{array}{c}\mathrm{DRC}= \\
8 \%\end{array}$ \\
\hline 55 & 74.1 & 74.2 & 74.1 & 6.6 & 6.6 & 6.6 & 5.5 & 5.5 & 5.5 & 13.8 & 13.8 & 13.8 \\
\hline 60 & 50.4 & 50.4 & 50.3 & 9.9 & 9.9 & 9.9 & 9.9 & 9.9 & 9.9 & 29.8 & 29.7 & 29.8 \\
\hline 61 & 44.7 & 44.8 & 44.7 & 10.6 & 10.6 & 10.6 & 10.9 & 10.9 & 10.9 & 33.7 & 33.6 & 33.8 \\
\hline 62 & 33.4 & 33.4 & 33.3 & 7.4 & 7.4 & 7.4 & 15.3 & 15.3 & 15.4 & 43.9 & 43.8 & 44.0 \\
\hline 63 & 28.5 & 28.6 & 28.4 & 7.9 & 7.9 & 7.8 & 16.0 & 16.0 & 16.0 & 47.6 & 47.5 & 47.7 \\
\hline 64 & 23.0 & 23.1 & 22.9 & 7.6 & 7.6 & 7.5 & 16.4 & 16.4 & 16.4 & 53.0 & 52.9 & 53.1 \\
\hline 65 & 15.9 & 15.2 & 17.1 & 7.4 & 6.9 & 8.3 & 17.1 & 17.3 & 16.7 & 59.6 & 60.5 & 57.9 \\
\hline 66 & 13.0 & 12.5 & 13.9 & 7.8 & 7.5 & 8.4 & 17.1 & 17.3 & 16.8 & 62.1 & 62.7 & 60.9 \\
\hline 67 & 10.8 & 10.5 & 11.6 & 7.5 & 7.3 & 7.9 & 17.0 & 17.1 & 16.8 & 64.6 & 65.0 & 63.8 \\
\hline 68 & 9.2 & 8.9 & 9.8 & 7.4 & 7.3 & 7.7 & 17.1 & 17.2 & 16.9 & 66.2 & 66.5 & 65.6 \\
\hline 69 & 7.9 & 7.7 & 8.4 & 8.3 & 8.3 & 8.4 & 16.6 & 16.7 & 16.5 & 67.2 & 67.3 & 66.8 \\
\hline
\end{tabular}


Table 12: Effects of Different Delayed Retirement Credits, Actual vs. 3\% vs. 8\%, on Selected Flows Among Various Retirement States (Assumes Actual Early and Normal Retirement Ages, Actual Earnings Test and 100 Percent of Formula Benefits)

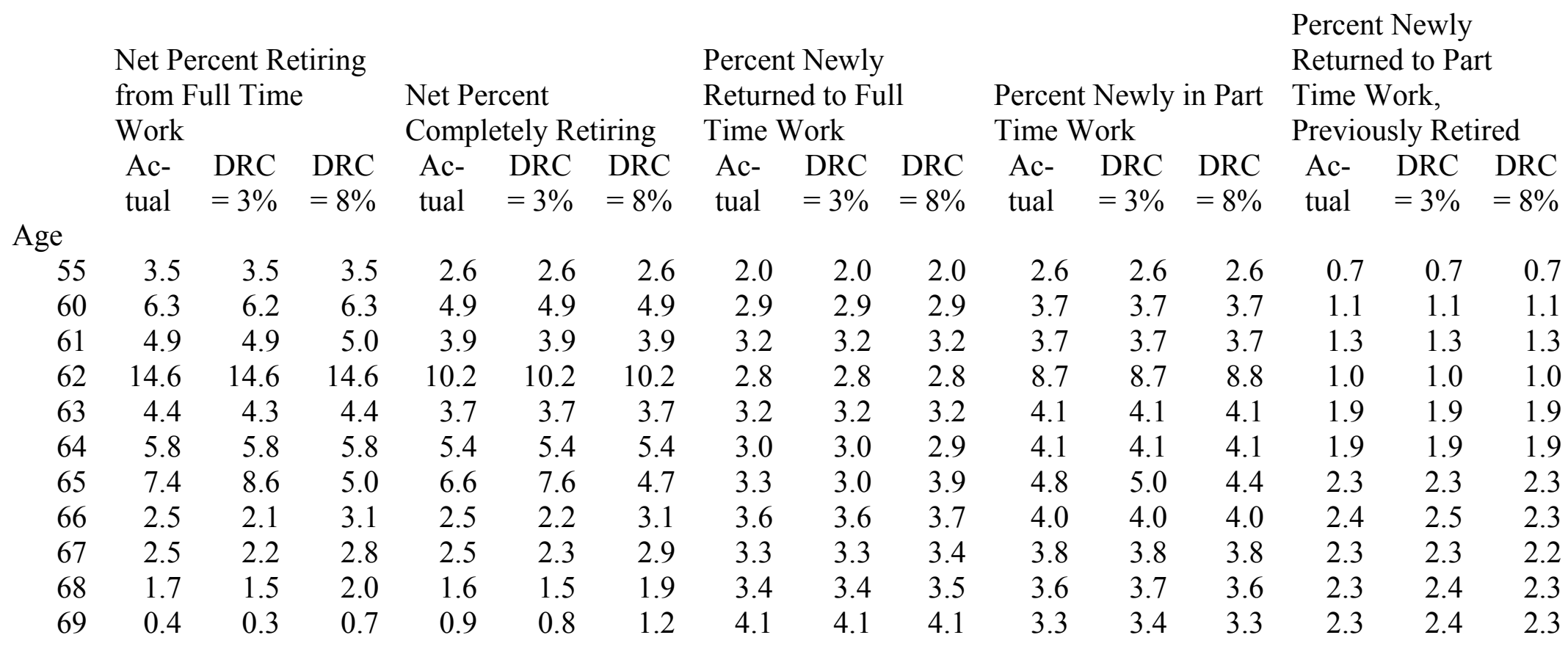


Table 13: Selected Cumulative Flows

\begin{tabular}{|l|l|l|l|}
\hline & $\begin{array}{l}\text { Percent returning to full time } \\
\text { work after full or partial } \\
\text { retirement }\end{array}$ & $\begin{array}{l}\text { Percent returning to part time } \\
\text { work after full retirement }\end{array}$ & $\begin{array}{l}\text { Percent returning to full time } \\
\text { work after full or partial } \\
\text { retirement, or returning to part } \\
\text { time work after full retirement }\end{array}$ \\
\hline $\begin{array}{l}\text { Base, ER Age }=62 \text {; Actual NR } \\
\text { Age; Actual Earnings Test; } \\
\begin{array}{l}100 \% \text { of Formula Benefit; } \\
\text { Actual DRC }\end{array}\end{array}$ & 35.5 & 19.4 & 46.3 \\
\hline ER Age $=64$ & 36.5 & 18.7 & 46.5 \\
\hline NR Age $=65$ & 35.5 & 19.4 & 46.2 \\
\hline NR Age $=67$ & 36.3 & 19.6 & 47.1 \\
\hline Earnings Test in all years & 34.9 & 19.6 & 45.9 \\
\hline $\begin{array}{l}\text { Earnings Test only before } \\
\text { normal retirement age }\end{array}$ & 36.1 & 19.1 & 46.6 \\
\hline No Earnings Test & 36.0 & 18.5 & 46.2 \\
\hline $75 \%$ of formula benefit & 35.8 & 18.7 & 45.7 \\
\hline DRC $=3 \%$ & 35.4 & 19.5 & 46.2 \\
\hline DRC $=8 \%$ & 36.0 & 19.2 & 46.5 \\
\hline
\end{tabular}




\section{Appendix}

Appendix Table 1: Reasons for Deletions of Observations

Males married in 1992

Divorced or widowed after age 35

Spouse not interviewed in 1992

Respondent does not have a career job

Ambiguity about whether jobs are ss covered

No FT earnings in ss record and no self-reported earnings

No self-reported earnings, and ss earnings over limit

Relatively large business assets

No Pension Provider record in last job

FT years unavailable for spouse

$\begin{array}{rr}\text { Observations } & \text { Observations } \\ \text { Dropped } & \text { Left } \\ & 4,928 \\ 639 & 4,289 \\ 133 & 4,156 \\ 497 & 3,659 \\ 49 & 3,610 \\ 36 & 3,574 \\ 31 & 3,543 \\ 291 & 3,252 \\ 865 & 2,387 \\ 156 & 2,231\end{array}$

